\title{
Determining the source of African dust transported to the Tropical Atlantic Ocean and its associated Fe mineralogy
}

\author{
ANNE E BARKLEY ${ }^{1}$, ALI POURMAND ${ }^{1}$, ARASH \\ SHARIFI $^{1}$, AMANDA OEHLERT ${ }^{2}$, COLLEEN BROWN $^{1}$, \\ RAVI KUKKADAPU ${ }^{3}$, MARK BOWDEN ${ }^{3}$, KATHY \\ PANECHOU $^{4}$, JOSEPH M. PROSPERO ${ }^{5}$, ANDREW AULT ${ }^{6}$ \\ AND CASSANDRA GASTON ${ }^{1}$ \\ ${ }^{1}$ Rosenstiel School for Marine and Atmospheric Science \\ (RSMAS), University of Miami \\ ${ }^{2}$ Bahamas Marine EcoCentre, RSMAS, University of Miami \\ ${ }^{3}$ Pacific Northwest National Laboratory \\ ${ }^{4}$ ATMO-Guyane \\ ${ }^{5}$ RSMAS/MAC University of Miami \\ ${ }^{6}$ University of Michigan \\ Presenting Author: abarkley@rsmas.miami.edu
}

Primary productivity in the tropical North Atlantic Ocean (NAO) is limited by the availability of nitrogen $(\mathrm{N})$, which is produced by $\mathrm{N}$-fixers who are co-limited by iron (Fe) and phosphorus. Deposition of African dust particles to the ocean is thought to stimulate primary productivity by providing Fe, thus enhancing the sequestration of carbon dioxide into the ocean. The magnitude of the impact on productivity depends on the mineralogy and oxidation state of Fe-bearing particles. These properties, however, have not been well studied in dust transported to the western NAO during boreal winter. Additionally, there have been few efforts to identify the locations of the sources of the dust transported to South America despite source location predicting the properties of Fe-bearing compounds. In this work, we characterize two years of transported African dust that was collected in Cayenne, French Guiana, located on the northeast coast of South America. Using radiogenic isotopes $\left({ }^{87} \mathrm{Sr} /{ }^{86} \mathrm{Sr},{ }^{143} \mathrm{Nd} /{ }^{144} \mathrm{Nd}\right)$ and a mixing model, we identify several major dust source regions and quantify their relative impact on our samples. Results indicate that our samples are mixes of multiple sources from western and central Sahara and sometimes include dust from the Bodele Depression. Additional evidence of paleolake transport was found using microscopy, which showed freshwater paleo-diatoms in diatomite, which also contained Fe-rich dust inclusions. Using radiogenic lead $(\mathrm{Pb})$ isotopes, we present the seasonal pattern of dust and biomass burning products transported to South America, which is important for understanding the seasonality of soluble $\mathrm{Fe}$ deposition to the western NAO. Additionally, we use Mössbauer spectroscopy and XRD to determine the mineralogy and oxidation state of $\mathrm{Fe}$-bearing compounds that are transported to Cayenne. We find Fe-mineralogy of the dust particles from each season is remarkably similar or varies slightly, and it is primarily a composite of hematite, readily bioavailable Fe forms of small-particle goethites and ferrihydrite with likely associated with organic matter associations, and mica with some Fe(II), which has implications for productivity in the western NAO and 